\title{
Quality of project financed by the European Union structural funds
}

\author{
Ewa Kozień ${ }^{1, *}$ \\ ${ }^{1}$ Cracow University of Economics, Faculty of Economics and International Relations, Department of \\ Management Strategy and Organisation, ul. Rakowicka 27, 31-510, Cracow, Poland
}

\begin{abstract}
The European Union structural funds even out the chances of development of particular regions in the European Union. Entities applying for additional financing from structural funds for various actions implemented in a form of projects must meet specific criteria. For this reason, the quality of prepared and implemented projects is of key importance. This paper draws the attention to meeting the requirements of a project at a stage of its preparation and implementation, taking into account the formal, contents-oriented and technical criteria and application of methodology of management, for effective absorption of European Union structural funds.
\end{abstract}

\section{Introduction}

The development of modern organizations [1] is determined by dynamic changes in the surrounding environment. Therefore the organizations, in order to maintain their competitive edge, undertake the actions implemented in a form of projects, which are assumed to contribute to achievement of beneficial change. However, due to limited resources, organizations apply for financing from European Union structural funds in order to implement their projects. One of essential elements in competition among organizations for financial support for their projects from structural funds is the quality of their preparation and implementation. This paper formed the following thesis - the quality of the project related to the formal, contents-oriented and technical preparation and welldeveloped methodology of its implementation increases the chances for additional financing for the project from the European Union structural funds.

\section{Structural funds as the aid from the European Union in co- financing projects}

Currently Poland is the greatest beneficiary of the European Funds. In the years 2014-2020 the European Union earmarked 82,5 billion Euro for Poland. The funds in Poland are spent for projects related to transport infrastructure, innovativeness, environmental protection, power generation, education, culture, employment and counteracting social exclusions [2].

\footnotetext{
*Corresponding author: koziene@uek.krakow.pl
} 
In the period of programming for the years 2014-2020 the instrument of implementation of the European Union structural policy are the structural and investment funds, including the following funds which can be used for co-financing the projects [3]:

- European Regional Development Fund finances the investments in infrastructure and development of potentials of the regions by implementation of projects regarding: building infrastructure of educational nature and in the scope of natural environment, construction and modernization of roads as well as supporting competitiveness of small and medium businesses.

- European Social Fund supports activities connected with development of employment market and human resources by preparation of projects related to the improvement of quality of educational system, training of specialists and business community as well as training unemployed persons.

- European Agricultural Fund for Development of Rural Areas supports agriculture as a result of implementation of projects concerning the improvement of conditions of life in rural communities and their development, differentiation of production and assistance for agricultural and food production sector.

- European Marine and Fishing Fund supports projects connected with renovation of fishing fleet, improvement in fish processing and marketing actions popularizing seafood.

Within the European Union structural policy the objectives and legal framework have been developed, which have been specified in the Regulation of the European Parliament and the Council (EU) No. 1303/2013 of 17 December 2013, establishing common legislation concerning the European Regional Development Fund, European Social Fund, Cohesiveness Fund, European Agricultural Fund for the Development of Rural Areas and European Marine and Fishing Fund as well as the legislation establishing general provisions concerning the European Regional Development Fund, European Social Fund, Cohesiveness Fund and European Marine and Fishing Fund and abrogating the regulation of the Council (EC) No. 1083/2006 [4].

The objectives of the EU structural policy strengthen the connection between structural and investment funds within the „Europe 2020" strategy. The connection of European structural and investment funds for the 2014-2020 programming period with the „Europe 2020 " strategy, implemented in the years 2010-2020, involves coordination of actions in time as well as convergence of designated goals. Within the formed „Europe 2020” strategy three goals have been designated [3]:

Goal 1 - Intelligent development including the following thematic goals:

- support of scientific research, technological development and innovations,

- increase of availability, application and quality of IT and communication technologies,

- strengthening of competitiveness of small and medium business sector.

Goal 2 - Sustainable development focused on:

- preservation and protection of natural development and support of effective management of resources,

- promotion of adjustment to climate changes, prevention of hazards and risk management,

- supporting the conversion to low-emission economy,

- promotion of sustainable transport.

Goal 3 - Development promoting social inclusion, such as:

- promotion of lasting and high quality employment as well as supporting workforce mobility,

- promotion of social inclusion and fighting poverty and all forms of discrimination,

- investing in education, training (including vocational training) aimed at improvement of skills and continuous learning, 
- strengthening the skills of institutional public authorities and interested parties as well as effectiveness of public administration.

Effectiveness of entities applying for support from structural funds requires an applicant to understand the nature of the project and possess knowledge from the scope of quality management at particular stages of preparation and implementation of a project.

\section{Project quality}

Total Quality Management philosophy finds practical application while preparing and implementing a project. A project, as an action with unique and temporary character, [5] is described by basic parameters i.e. meeting requirements, time and cost. Meeting requirements refers to quality requirements pertaining to a project. Interpretation of quality in specialist literature varies. Most generally, quality is perceived as a degree of adjustment of a given item to object's expectations. P.B. Crosby [6], E.W. Deming [7], defining quality, draw the readers' attention to such elements as: compliance with requirements, reliability, cost. More precisely, quality is interpreted by product, usability, value and normative approach. One should note that normative quality is of universal nature, it combines the remaining approaches, explaining quality as a collection of inherent meeting of requirements [8]. What is the quality of a project then? - one may directly define the project quality as the ability to meet requirements specified as each stage of its preparation and implementation. Many interconnected elements have impact on project quality, such as:

- surrounding milieu - political, economic, institutional, technical, social and cultural,

- preparation and implementation of a project, hence a definition of methodology of project management and actions in the field of management of scope, integration, time, costs, quality, human resources, communication, risk, orders, involvement, knowledge.

Moreover, the level of project quality may be also viewed in the aspect of effectiveness of implementation of the goal of the project, economy, benefits and social effects.

From the point of view of effectiveness in obtaining EU structural funds it is crucial to meet requirements connected with preparation and implementation of a project. Therefore it is necessary to consider the issue of project quality with a view to requirements concerning the following three criteria:

- formal,

- contents-oriented and technical,

- methodology of management.

Based on the author's own research regarding projects in the field of infrastructure, environmental protection, science and education, culture, sport as well as activization and social integration, implemented in selected communes in Poland and co-financed from the EU structural funds, the following requirements, essential from the formal point of view have been pointed out, which improved the quality of the projects being prepared:

- cohesiveness of project goals with the formulated strategy (of the state, commune or a company),

- compliance of the norms of EU and domestic law,

- innovativeness concerning methods of implementation and results of the project,

- completeness of an application (compliance of a hard copy of an application form with an electronic form,

- completeness of attachments,

- correct specification of qualified costs,

- structure of sources of project financing compliant with the amount and level specified in the documentation concerning a given action.

However, in the scope of contents-oriented and technical criteria, the qualitative requirements of the project concern: 
- specification of goals and actions and descriptions of anticipated results,

- specification of added value and continuity of benefits following the completion of the project. Added value means actual benefits and usability of a project, subject to verification (economic and functional continuity), i.e. ex post evaluation after several years from the moment of project completion.

- system of monitoring and assessment which serves the verification of preparation and verification of the project. Qualitative and quantitative indicators are evaluated at each stage of project implementation. Therefore one must evaluate the project quality ex ante, on - line and ex post.

- resources. In the project the coordination in time of human resources, asset, finance, information - is crucial. Quality of the project in a special way refers to human resources, i.e. the possessed specialist knowledge connected with subject matter of the project as well the knowledge connected with project management as well as skills and experience.

- structure of project financing, which specifies the percentage share of the entity's own contribution (special purpose domestic subsidies, loans, credits) as well as money coming from structural funds. Moreover, the requirements of the developed cost estimate concern an important issue of division of costs into qualified and non-qualified costs, which cannot be covered from structural funds,

- project implementation schedule, i.e. the necessity of coordination of project tasks in time in order to eliminate delays (EVM method [9]).

The last criterion concerning the issue of quality and the constant element of structure of project management methodologies was considered based on analysis of selected methodological approaches. It is worth stressing the fact that the European Committee noticed a problem of effectiveness of participation of particular member states in implementation of aid policy. As a result of identification of committed errors during the preparation of projects for implementation, it proposes the application of methodological solutions improving this process, and which the beneficiaries and executive staff may take advantage of. The European Union does not impose on the beneficiaries any specific methodology assisting project management, but it encourages them to choose proven methodologies. In the Project Cycle Management [10] method which had been approved by the European Committee the aspect of project quality is stressed in the scope of assessment of validity and compliance of the problem with EU development policy, a method of its solution as well as continuity and quality of project results.

However, in the methodology: A Guide to the Project Management Body of Knowledge, $\mathrm{PMBoK}{ }^{\circledR}[8]$ the field of quality management assures that as a result of the process of planning, quality assurance and monitoring, the project will meet quality expectations perceived in a category of client satisfaction, product usability as well as compliance with regulations, norms and legal provisions. Quality requirements of the project concern many standards, sometimes exceeding the subject matter of the project, and including the sphere of management, access to information, technical norms as well as ecological norms.

However, in a group of agile methodologies (i.e. Scrum), which are based on iterative and incremental building of results, the care for project quality is based each time in increases [11]. The significant advantage of agile methodologies means continuous presence of a client who evaluates the current quality of particular project results. It should be emphasized that agile methodologies treat exceeded deadlines and costs of project implementation as a certain ,norm”, stressing decisively the project scope and quality what is confirmed by research conducted by a company called VersionOne [12], where the increase of benefits arising from application of agile approach to project management in the scope of improvement of project results quality was defined at the level of $80 \%$. 
Analyzing selected project management methodologies one may find that they include a key parameter of meeting qualitative requirements concerning project results. Due to the implementation of hard (infrastructural) as well as soft (e.g. trainings) projects which are practically complicated as well as varied - with a view to their subject matter - connected with the investment in human development, qualitative requirements constitute a vast catalogue specified in relation to a given type of project. Currently the directive of effective project implementation is narrowed down to implementation of a project well (meeting qualitative requirements), quickly (time) and cheaply (cost). Taking into account the benefits arising from agile approach in the scope of project quality one must recommend this approach in implementation of not only innovative and IT projects. It should be emphasized that both in traditional and agile methodologies the mutual interdependencies of parameters are focused with a view to qualitative requirements of the project

\section{Conclusions}

Project quality is of key importance in the aspect of obtaining funds from the EU structural funds. The principles of launching structural funds (i.e. principle of concentration, partnership, compliance, programming and additionality) translate into requirements concerning the implementation of projects which were granted subsidies from the European Union structural funds. It should be emphasized that only correctly prepared and implemented projects, i.e. the projects which meet basic EU requirements in practice stand a chance for additional financing. In order to avoid the rejection of valuable projects on formal grounds one should approach their preparation and implementation holistically, taking into account the issue of formal requirements, contents-related justification and methodological approach to project quality.

Meeting qualitative expectations in relation to the final product is possible when the quality is not omitted but becomes an integral element of the project management process, what can be perceived in the proposed methodological approach. It should be stated that the project quality makes it possible to obtain money from EU funds, to achieve success from implementation of the project itself, it also impacts the potential for development of organizations and regions.

Quality management is one the most important factor impacting on the value of scientific investigation results, especially in these areas, where a laboratory scale research meets industrial requirements e.g. materials science [13-26], machining [27, 28], biotechnology [29] or huge enterprises [30-32]. This is clearly recognized in scientific publications in the field of management [33-35].

\section{References}

1. E. Kozien, Identification of stage phase growth in the checklist method using different statistical parameters, Economic and Social Development. Book of Proceedings, 538 (Prague, 27-28 April 2017)

2. https://www.funduszeeuropejskie.gov.pl/strony/o-funduszach/zasady-dzialaniafunduszy/fundusze-europejskie-w-polsce/

3. European structural and investment funds for years 2014-2020: Official texts and comments (European Commission, 2016)

4. Dz.U., L 347 (20.12.2013)

5. P. B. Crosby, Running Things: the Art of Making Things Happen (Mc Graw-Hill, New York, 1986) 
6. E. W. Deming, Quality, Productivity and Competition Position (MIT Press, Cambridge, Massachusetts, 1982)

7. ISO 9000:2000

8. A Guide to the Project Management Body of Knowledge, 5th Edition (Project Management Institute, Newtown Square, PA, 2013)

9. Practice Standard for Earned Value Management (Project Management Institute, Newtown Square, PA, 2011)

10. Project Cycle Management Handbook (European Commission, March 2004)

11. K. Schwaber, M. Bendle, Agile Software Development with Scrum (Prentice Hall, 2001)

12. VersionOne. The $10^{\text {th }}$ Annual State of Agile Report, www.versionone.com (2015)

13. J. Korzekwa, P. Wawrzala, R. Skulski, Eur. Phys. J.-Spec. Top. 154, 127 (2008)

14. A. Dudek, C. Kolana, Solid State Phenom., 165, 25 (2010)

15. T. Pieczonka, J. Kazior, A. Szewczyk-Nykiel, M. Hebda, M. Nykiel, Powder Metall., 55, 354 (2012)

16. N. Radek, J. Pietraszek, B. Antoszewski, Adv. Mat. Res.-Switz., 874, 29 (2014)

17. R. Ulewicz, F.R. Novy, J. Balk. Tribol. Assoc., 22, 1147 (2016)

18. A. Gadek-Moszczak, Image Anal. Stereol., 36, 151 (2017)

19. A. Gadek-Moszczak, Image Anal. Stereol., 36, 207 (2017)

20. M. Ulewicz, U. Lesinska, M. Bochenska, Physicochem. Probl. Mi. 44245 (2010)

21. T. Lipinski, Solid State Phenom., 163183 (2010)

22. M. Ulewicz, E. Radzyminska-Lenarcik, Physicochem. Probl. Mi., 46, 119 (2011)

23. T. Lipinski, A. Wach, Proc. 23 ${ }^{\text {rd }}$ International Conference on Metallurgy and Materials, Brno, Czech Republic, May 21-23, 738 (2014)

24. D. Klimecka-Tatar, S. Borkowski, P. Sygut, Arch. Metall. Mater., 60, 735 (2015)

25. D. Klimecka-Tatar, G. Pawlowska, M. Sozanska, Arch. Metall. Mater., 60153 (2015)

26. R. Dwornicka, N. Radek, M. Krawczyk, P. Osocha, J. Pobedza, Proc. 26th Int. Conf. on Metall. and Mater. - METAL, Brno, Czech Republic, May 24-26, 1252 (2017)

27. J. Pietraszek, Proc. $6^{\text {th }}$ Int. Conf. Neural Net. Soft Comput., Zakopane, Poland, Jun $11-15,2002,250$ (2003)

28. I. Dominik, J. Kwasniewski, K. Lalik, R. Dwornicka, Proc. $32^{\text {nd }}$ Chinese Control Conf. (CCC), Xian, China, July 26-28, 7505 (2013)

29. J. Pietraszek, E. Skrzypczak-Pietraszek, Adv. Mat. Res.-Switz. 874, 151 (2014)

30. P. Osocha, Adv. Mat. Res.-Switz. 874, 89 (2014)

31. E. Baussan, Phys. Rev. Spec. Top.-Accel. Beams 17, 031001 (2014)

32. R. Dwornicka, Adv. Mat. Res.-Switz. 874, 63 (2014)

33. R. Ulewicz, J. Selejdak, S. Borkowski, M. Jagusiak-Kocik, Proc. $22^{\text {nd }}$ International Conference on Metallurgy and Materials, Brno, Czech Republic, May 15-17, 1926 (2013)

34. R. Ulewicz, Proc. Int. Conf. Path Forward for Wood Products: A Global Perspective, Baton Rouge, LA, Oct 05-08, 51 (2016)

35. A. Pacana, R. Ulewicz, Polish J. Environ. Studies, 16, 165 (2017) 